\title{
The Importance of Investigating Tumor Biology and Biomarkers in Pleural Effusions
}

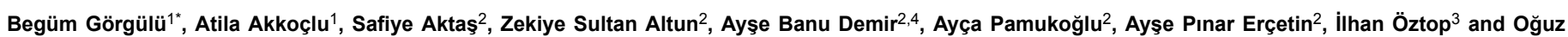
Kılınç $^{1}$

${ }^{1}$ Department of Chest Diseases, Faculty of Medicine, Dokuz Eylul University, Izmir, Turkey

${ }^{2}$ Department of Basic Oncology, The Institute of Oncology, Dokuz Eylul University, Izmir, Turkey

${ }^{3}$ Department of Oncology, Faculty of Medicine, Dokuz Eylul University, Izmir, Turkey

${ }^{4}$ Department of Medical Biology, Faculty of Medicine, University of Economics, Izmir, Turkey

*Corresponding author: Begüm Görgülü, Department of Chest Diseases, School of Medicine, Dokuz Eylul University, Izmir, Turkey, Tel: +905366195141; E-mail: drbegumgorgulu@gmail.com

Rec Date: August 30, 2018, Acc Date: October 19, 2018, Pub Date: November 03, 2018

Copyright: @ 2018 Görgülü B, et al. This is an open-access article distributed under the terms of the Creative Commons Attribution License, which permits unrestricted use, distribution, and reproduction in any medium, provided the original author and source are credited.

\begin{abstract}
Introduction: Pleural fluids can form in several diseases. In cancer patients particularly; diagnosing pleural fluids accurately can affect treatment and prognosis. Nevertheless, despite many studies carried out, it is difficult to distinguish malign-benign fluids and invasive processes are required. It was aimed in our study that biomarkers were analyzed by utilizing nucleic acid duplication method in pleural fluids attained by less invasive method as pleural puncture.
\end{abstract}

Methods: Of 54 patients who had applied to Chest Diseases Department and had been carried out pleural puncture for differential diagnosis, their pleura fluid samples were analyzed in Basic Oncology laboratory. Biomarkers were evaluated by examining expressions of 11 genes with PCR analysis.

Results: 45 (83\%) out of 54 cases involved in the study had cancer diagnosis. $34 \%$ of malignancies were lung adenocarcinoma and $24 \%$ were breast cancer. In $53.4 \%$ of the cases with lung adenocarcinoma, TTF1 was observed; napsin A positivity was seen in $67 \%$ of cases with squamous cell carcinoma; both napsin A positivity and TTF1 positivity were determined in $67 \%$ of cases. ER was positive in $45 \%$ of cases with breast cancer. In the fluid analysis of 4 cases who were ER positive initially, received hormonotherapy and thereafter had pleural fluid development; ER was determined as negative, CK7 was positive.

Discussion and Conclusion: When the results of our study were evaluated, we think that if pleural fluid cytology workup result in cases (who receive treatment due to primary tumor or have been operated) assumed to have malignant pleurisy clinically with high likelihood is negative, it is recommended that advanced examination should be carried out (PCR analysis) and if the pleural fluid cytology workup result is positive, it will contribute to the diagnosis in analyzing biomarkers specific to tumor for the determination of primary tumor-pleural metastasis connection.

Keywords: Pleural effusion; Biomarkers; Real-time PCR; Neoplasm; Metastasis; Tumor biology

\section{Introduction}

Pleural fluids are capable of forming in various diseases such as pneumonia, cancer, heart failure, tuberculosis [1]. In the differential diagnosis of malignant pleurisies from these diseases, biopsy for primary tumor and if necessary surgical procedures (Chest Surgery with Video Aid (VATS), thoracoscopy) [2] and further cytologic examination (cell culture, immunohistochemistry, Polymerase Chain Reaction (PCR analysis)) are performed. Pleural fluid is known to contain plasma proteins together with inflammatory and proteins that epithelium and cancer cells release to the setting [3]. The fluid being rich in terms of proteins released and/or related to membrane and having specific biomarker for numerous diseases shows that it is an important material [4]. Since analyzing all new biomarkers includes all biological processes from gene expressions to protein changes, wide patient series and intensive molecular, proteomic studies are required.
In our study, it was aimed that different biomarkers in pleural fluids with malign and benign cause should be examined with nucleic acid multiplication method (PCR analysis) and evaluated in terms of their contribution to diagnosis.

\section{Materials and Methods}

Our study was initiated with the decision of 2013/13-02 numbered ethical committee dated as 11.04.2013 and with 947-GOA protocol number and with 2015. KB. SAG. 007 numbered financial support by DEU Scientific Research Projects Coordination Unit. Informed consent was obtained from the cases concerning their wish to be included in the study. Pleural fluid samples were attained for differential diagnosis from 54 cases aged over 18 who had applied to Dokuz Eylul University Chest Diseases Department. Pleural fluid sample from 54 patients at Oncology Institute Basic Oncology Department laboratory was included in the study. During routine diagnostic procedures, some pleural fluid samples obtained by injector 
from intercostal space were analyzed at basic oncology laboratory. No separate pleural fluid acquisition was applied to cases for this study.

\section{The molecular analysis of pleural fluids}

Pleural fluid samples were portioned into $50 \mathrm{~mL}$ falcon tubes and serum part of the fluid was collected by centrifuging at $1600 \mathrm{rpm}$ for 7 minutes. These serum samples were kept at $-80^{\circ} \mathrm{C}$ until biomarker analysis. For total RNA isolation, cells were re-suspended in $200 \mu \mathrm{L}$ Phosphate-buffered saline (PBS). $400 \mu \mathrm{L}$ lysis and bonding tampon were added and they were vortexed for 15 seconds and attached to collection tube with high pure filter. The sample was transferred to upper tube with filter and centrifuged for 15 seconds. The tube with filter was removed from the collection tube. The same tubes were attached again after the fluid in collection tube had been removed. For every sample, $90 \mu \mathrm{L}$ DNase intubation tampon was added to reaction tube. $10 \mu \mathrm{L}$ Dnase was added and mixed and this mixture was added to tube with filter and incubated for 15 minutes in room temperature. 500 $\mu \mathrm{L}$ washing tampon I was added to the tube with filter and centrifuged at $8000 \mathrm{~g}$ for 15 seconds. After the fluid had been removed from the lower collection tube, the same tubes were attached again. $500 \mu \mathrm{L}$ washing tampon were added to the tube with tampon II and centrifuged at $8000 \mathrm{~g}$ for 15 seconds. After the fluid accumulated in the lower collection tube had been removed, the same tubes were mounted again and $200 \mu \mathrm{L}$ washing tampon II was added to the tube with filter and centrifuged at maximum speed. Later, the collection tube was disposed and the tube with filter was mounted to new $15 \mathrm{~mL}$ microcentrifuge tube. For RNA elution, 50-100 $\mu \mathrm{L}$ elution tampon was added to the filter tube. It was centrifuged at $8000 \mathrm{~g}$ for 1 minute. RNA that wanted to be acquired would be in the lower $1.5 \mathrm{~mL}$ microcentrifuge tube. RNA was kept at $-80^{\circ} \mathrm{C}$ to be used in cDNA synthesis and then for Real-time PCR study and their amounts were measured at Qubit device. RNA amounts obtained from some samples were very low due to hypoplasia. Therefore, maximum amount of RNA that could be attained from RNA samples for cDNA conversion was obtained and cDNA synthesis was implemented with iScriptTM cDNA Sythesis Kit $\left(\mathrm{BioRad}^{\circ}\right)$ as the producer firm explained. The quality of cDNA was tested with Real-time PCR reaction before it had been put into the array. The buffer stock including $0.1 \mu \mathrm{M} 1 \mathrm{X}$ primary-enzyme mixture was prepared and kept at $-20^{\circ} \mathrm{C}$ until its use. cDNA SYBR Green ${ }^{\circ}$ Master mix was prepared and it was put into 1 and $5 \mathrm{ml}$ microcentrifuge tubes which were vortexed and distributed to every well of plates with 96 wells involving $9 \mu \mathrm{L}$. On top of the mixture, $1 \mu \mathrm{L}$ was added from primary-enzyme stock mixture prepared before. The surface of PCR-array plate with $10 \mu \mathrm{L}$ final volume in total was covered with seal, it was spinned down at $2000 \mathrm{rpm}$ for 1 minute and PCR was performed using High Pure PCR Clean/extraction kit by Roche. PCR conditions: Primary concentration $0.1 \mu \mathrm{M}$, Programme: $95^{\circ} \mathrm{C}-10 \mathrm{~s}$, $58^{\circ} \mathrm{C}-45 \mathrm{~s}$ (45 cycles). Attained Cq values were analyzed in 'Qiagen Bioscience" programme. RNAs obtained were converted into cDNA and cDNAs were added to PCR mixture by avoiding DNA contamination carefully. Real-time PCR analysis became a kit prepared for effective inflammatory cytokines and receptors for immune response to be performed. In the data analysis, information was obtained regarding the expressions of indicators below (Table 1). Biomarkers were arranged to determine the most common malignant pleural effusion reasons [5-7].

Thyroid Transcription Factor-1 (TTF1): As expressed from mature lung and thyroid tissue and embryonic epithelial cells, it is a nuclear transcription protein of $\mathrm{Nkx} 2$ gene family. TTF-1 plays an important role in the early differentiation and morphogenesis of developing thyroid, lung, brain and hypophysis. TTF-1 expression is seen at high rates of lung and thyroid cancers. In some studies, it was reported that TTF-1 was expressed at different volumes in different lung carcinoma types. TTF-1 shows immunoreactivity in lung adenocarcinoma, nonmucinous adenocarcinoma in particular. This protein with sensitivity $70 \%$, specificity $100 \%$, provides the distinction of adenocarcinomas that makes metastasis to lung (except for thyroid malignancies) from primary lung adenocarcinomas. Thyroglobuline is checked additionally for thyroid malignancy $[8,9]$. While TTF- 1 expression is seen less frequently in large cell carcinoma of lung, this rate is lower in squamous cell carcinoma of lung. TTF-1 expression is reported at high rates such as $81-100 \%$ in small cell carcinoma of lung. In non-small cell lung cancer, however, TTF-1 expression is present at $10-80 \%$ rate [10].

\begin{tabular}{|l|l|}
\hline \multicolumn{2}{|l|}{ List of Biomarkers } \\
\hline Thyroid Transcription Factor-1 (TTF1) & Calretinin \\
\hline Napsin A & Synaptophysin (SYN) \\
\hline Estrogen receptor (ER) & CD19 \\
\hline Chromogranin A (CgA) & CD3 \\
\hline Cytokeratin 7 (CK7) & Cytokeratin 5/6 (CK5/6) \\
\hline Leukocyte common antigen (LCA-CD45) & \\
\hline
\end{tabular}

Table 1: Biomarkers viewed with PCR array analysis.

Napsin A: It is an aspartic proteinase expressed from type II pneumocytes with proximal and distal renal tubule. It is expressed more than $80 \%$ in lung adenocarcinomas. It can be used as an addition to TTF-1 [11]. Napsin A is more sensitive than TTF-1 in primary lung cancer. If TTF-1 and Napsin A are positive together, lung adenocarcinoma is considered.

Calretinin: It is protein dependent to $29 \mathrm{dDa}$ calcium with EF-el structure $[11,12]$. It is expressed in peripheral and central nerve tissues and it has expressions in mesothelial cells. In some studies, calretinin is shown to be a positive marker for mesothelioma $[13,14]$.

Estrogen Receptor (ER): Estrogen receptors are intracellular proteins and taken into cell depending on their concentration change and bind to hormone molecule selectively and form hormone-receptor complex. Activating hormone-receptor complex binds to short DNA sequences named as hormone response elements specifically in nucleus and performs transcription providing physiologic hormone activity [15]. In breast cancers, estrogen hormone has mutagenic and promoter effect. Mutagenic effect of estrogen hormone is organized by receptors and in culture its mutagenic effect in breast cancer cells carrying functional estrogen receptor was proved [16]. Particularly breast and endometrium carcinoma, prognostic importance of estrogen receptors was determined in a group of neoplastic diseases. ER (+) tumors responds to hormonal treatment and they show better prognosis. In healthy lung tissue and lung tumors, there is pretty much evidence that estrogen receptors are expressed and lung cancer responds to estrogens with proliferation. In samples obtained from patients with NSCLC, antibodies specific to $\operatorname{Er} \beta$ demonstrate that these receptors are frequently expressed in NSCLC $[17,18]$.

Chromogranin A (CgA): Chromogranins are acidic glycoproteins found in neurosecretory granules. They are 3 types; A, B and C. Chromogranin is commonly found in secretory vesicles in all endocrine, neuroendocrine and nervous system of $\mathrm{CgA}$. CgA found 
together with peptide and amine hormones in these tissues where it takes charge in the regulation of secretory proteins is an acidic glycoprotein $[19,20]$. It is a general biomarker for CgA neuroendocrine cells depending on common expression in neuroendocrine system and high CgA levels are a helper in the determination of neuroendocrine tumors. It is established as positive in tumors such as gastric, pancreatic, small intestine and colorectal localization and small cell lung carcinoma, medullary thyroid carcinoma, neuroblastoma, pheochromocytoma, pituitary tumors, paraganglioma. In addition, it can be positive in such cancers as pancreatic adenocarcinoma, hepatocellular carcinoma, breast, colon, ovarian and prostate in small quantities [21].

Synaptophysin (SYN): It is a protein that forms a pore between synaptic vesicles composed of six polypeptides in synaptic vesicle membrane and plasma membrane. It is released from neuroendocrine tumors. Cg A and SYN are frequently used as an indicator in the diagnosis of neuroendocrine tumors of lung. All typical and atypical carcinoids are $\mathrm{CgA}$ and/or SYN positive. However, small cell lung cancer must be kept in mind that it can show negativity at $25 \%$ rate. Gastroenteropathic neuroendocrine tumor (GEP-NET) cells express proteins as phenotypic SYN and CgA [22].

CD19: These cells are lymphocytes with 7-10 $\mu \mathrm{m}$ diameters. In addition to other indicators, they carry surface immunoglobulin, particularly IgM and $\operatorname{IgD}$ and at a low rate, $\operatorname{IgG}$ and $\operatorname{IgA}$. They are determined as positive in CD19, B-cell lymphoma, leukemia and inflammations.

CD3: CD3 is expressed as heterodimer and accounts for 3 subunits called as $\delta, \varepsilon, \gamma$ and $\zeta$ subunit connected to them as homodimer. Every subunit includes immunoreceptor tyrosine-based activation motif (ITAM) with amino acid structure that places tyrosine residuals individually. ITAM tyrosines are a key for $\mathrm{CD} 3$ and $\zeta$ chains convey the signal. When $\alpha / \beta$ THR chains unite with peptide-MHC complex, they become phosphorylated. Following phosphorylation, ITAMs become a harbour for other proteins to commence signal cascade in T-cell activation. CD4 and CD8 proteins also play role in signal transmission [23]. It is determined as positive in CD3, lymphoma, leukemia and inflammations.

Leukocyte common antigen (LCA-CD45): It is positive in all lymphocytes; all lymphomas are stained positive. Follicular dendritic cells (FDC) are LCA positive [24].

Cytokeratin 5/6 (CK5/6): Cytokeratins are intermediate filaments and their real missions are to ensure cells to withstand mechanical stress. In humans, there are 20 different types of isotypes of cytokeratins. In squamous cell carcinomas, cytokeratin is $5 / 6$ positive together with many keratin types. Cytokeratins with high molecular weight (HMW) like CK5/6 and CK14 are known as basal cytokeratins as they are determined in basal layer cells. These HMW cytokines are established at $25 \%$ rate in grade 3 in-situ breast lesions and invasive breast cancer at $2-18 \%$ rate. Therefore, this breast cancer group is named as a group showing basal/myoepithelial phenotype. In addition, basaloid group is used as a synonym of basal-like [25].

Cytokeratin 7 (CK7): It is coded by KRT 7 gene. Type II cytokeratin is composed of basic or neutral proteins during the differentiation of basic and stratified epithelium tissues. This type II cytokins cover the spaces of internal organs, gland channels and inner layer of blood vessels. In lung adenocarcinomas, CK 7 positivity is observed. It is evaluated with CK 20 [6,26].

\section{The analysis of the data}

Statistical analysis was carried out by using SPSS 22.0 programme. $\mathrm{p}<0.05$ was statistically accepted as significant. In multigene analyses, $\mathrm{Cp}$ values were transformed into $\mathrm{Ct}$ values in the analysis sites of the firm concerned and compared with the gene expression profiles of testbased groups.

\section{Results}

In the study, certain amount of pleural fluid sample obtained for cytologic evaluation of 54 cases was reserved for the study. The demographical features of cases involved in the study were given in Table 2.

\begin{tabular}{|l|l|}
\hline Demographics & Values \\
\hline Age & $65.5 \pm 11.58$ \\
\hline Sex F/M (n) & $27 / 27$ \\
\hline Smoking +/- $(\mathrm{n})$ & $29 / 25$ \\
\hline Smoking (packet/year) & $53.9 \pm 24.87$ \\
\hline Cardiac disease & $48.10 \%$ \\
\hline Asthma & $9.30 \%$ \\
\hline COPD & $44.40 \%$ \\
\hline Pulmonary embolism & $7.40 \%$ \\
\hline
\end{tabular}

Table 2: Demographical and clinical features of the cases.

45 out of 54 cases included in the study had a malignant disease (Table 3). Parapneumonia was present in 4 patients, heart failure in 2 , chronic pleuritis in 2 and pleural fluid related to sarcoidosis in 1 . In the routine pathological evaluation of cases analyzed for diagnosis purposes, malignant cells were not seen in $44.4 \%$ of cases, however, malignant cells were observed in $55.6 \%$ of them.

\begin{tabular}{|l|l|l|}
\hline Cancer & $\mathbf{n}$ & $\%$ \\
\hline Lung adenocarcinoma & 15 & 33.6 \\
\hline Small cell lung carcinoma & 6 & 13.3 \\
\hline Lung carcinoid tumor & 1 & 2.2 \\
\hline Lung squamous cell carcinoma & 2 & 4.4 \\
\hline Breast cancer & 11 & 24.4 \\
\hline Overian adenocarcinoma & 2 & 4.4 \\
\hline Lymphoma & 3 & 6.7 \\
\hline Stomach adenocarcinoma & 1 & 2.2 \\
\hline Extrapulmonary squamous cell carcinoma & 2 & 4.4 \\
\hline Renal cell carcinoma & 1 & 2.2 \\
\hline Colon adenocarcinoma & 1 & 2.2 \\
\hline Total & 45 & 100 \\
\hline
\end{tabular}

Table 3: The distribution of cancer types of cases in malignant group. 


\begin{tabular}{|l|l|l|l|}
\hline Cancer & PCR negative $\mathbf{n}(\%)$ & PCR positive $\mathbf{n}(\%)$ & Total $\mathbf{n}(\%)$ \\
\hline Lung adenocarcinoma & $5(33.3)$ & $10(66.7)$ & $15(100)$ \\
\hline Small cell lung carcinoma & $3(50)$ & $3(50)$ & $6(100)$ \\
\hline Lung carcinoid tumor & 0 & $1(100)$ & $1(100)$ \\
\hline Lung squamous cell carcinoma & 0 & $3(100)$ & $3(100)$ \\
\hline Breast cancer & $2(18.2)$ & $9(81.8)$ & $11(100)$ \\
\hline Overian adenocarcinoma & $2(100)$ & 0 & $2(100)$ \\
\hline Lymphoma & 0 & $3(100)$ & $3(100)$ \\
\hline Stomach adenocarcinoma & $1(100)$ & 0 & $1(100)$ \\
\hline Extrapulmonary squamous cell carcinoma & 0 & $1(100)$ & $1(100)$ \\
\hline Renal cell carcinoma & $1(100)$ & 0 & $1(100)$ \\
\hline Colon adenocarcinoma & $1(100)$ & 0 & $1(100)$ \\
\hline
\end{tabular}

Table 4: cDNA-SYBR green master mix mixture and array kit results.

\begin{tabular}{|l|l|l|l|}
\hline \multirow{2}{*}{$\begin{array}{l}\text { Routine cytologic } \\
\text { evaluation results }\end{array}$} & \multicolumn{2}{|l|}{ PCR array results } & \multirow{2}{*}{ Total } \\
\cline { 2 - 3 } & Negative & Malignant & \\
\hline Negative & $16(66.7 \%)$ & $8(33.3 \%)$ & 24 \\
\hline Malignant & $8(26.7 \%)$ & $22(73.3 \%)$ & 30 \\
\hline Total & 24 & 30 & 54 \\
\hline
\end{tabular}

Table 5: PCR array results were compared with routine cytologic evaluation results $(\mathrm{p}=0.003)$.

TTFI in pleural effusions, Napsin A, ER, CG A, CK7, LCA-CD45 expressions were evaluated as negative and positive in accordance with cDNA-SYBR Green Master mix mixture and array kit results (Table 4).

In our study, TTF1 was determined as positive in $53.4 \%$ of cases with lung adenocarcinoma. While in lung squamous cell carcinoma, TTF1 positivity was determined at $66.7 \%$ rate, TTF1 positivity was not determined in none of the extrapulmonary malignancies. Napsin A positivity rate was found as $66 \%$ in lung adenocarcinoma. While napsin A positivity was found as $45 \%$ in breast cancer cases, TTF1 positivity was not identified in none of breast cancer cases. Calretinin positivity was seen at $33 \%$ in breast cancer; on the other hand, calretinin positivity was also determined in squamous cell carcinoma. ER was positive in $45 \%$ of cases with breast cancer. ER negative in pleural effusion developed after chemotherapy in 4 cases and determining CK7 made us think that ER-/CK7+ aggressive subgroup could have made a metastasis to pleura. ER was positive in squamous cell lung carcinoma at $33 \%$ rate in our study. There was CgA positivity in our one carcinoid tumor case. CgA positivity was seen in $16.7 \%$ of our cases with small cell lung carcinoma. In addition, LCA positivity was present at $33 \%$ rate in lymphomas. $11 \%$ positivity rate in nonmalignant group was thought to be related to inflammation. In $46 \%$ of cases with lung adenocarcinoma and $66.7 \%$ of cases with squamous cell carcinoma, CK5/6 positivity was determined. In the study, determining CD19 positivity at $66 \%$ rate in non-malignant pleural effusions made us think that it could be associated with the increase in

the number of lymphocytes due to inflammation. In total of 3 cases with lymphoma and 1 extrapulmonary squamous cell carcinoma, positivity was identified in CD19. In one lung carcinoid tumor case and in $33.3 \%$ of our cases with small cell lung cancer, synaptophysin was positive.

PCR array results were compared with routine cytologic evaluation result (Table 5).

When PCR array results and routine cytology results were evaluated; sensitivity in PCR was $73 \%$, specificity was $67 \%$, positive predictive value was $73 \%$, negative predictivity value was $67 \%$ and PCR general test power was found as $70 \%$.

\section{Discussion}

The distribution of cases with malignant pleural fluid was as follows: $33.6 \%$ was lung adenocarcinoma, $24.4 \%$ was breast cancer and $6.7 \%$ was lymphoma and these rates are similar to those in literature. The most common malignant effusion causes in literature are 35\% lung cancer, $23 \%$ breast cancer and $10 \%$ lymphoma [6].

In accordance with cytology results in our study, no malignant cells were seen in $44 \%$ of cases. Pleural fluids with no determined malignancy was thought to result from not having sufficient cells in samples that went to cytology and/or having pleural effusion regarding chemotherapy drugs, radiotherapy, infection.

TTF-1 was identified positive in 16 lung, 15 ovarian, 9 stomach, 8 colon and 8 breast cancers in $81 \%$ of cases. Nevertheless, TTF1 was not determined positive in extrapulmonary adenocarcinomas [26]. Kim et al. established TTF1 positive in $58 \%$ of 52 cases with lung adenocarcinoma and CDX2 positive in 30\% colon and stomach cancers [27]. In our study, TTF1 was positive in $53,4 \%$ of cases with lung adenocarcinoma and again it was determined positive in $66,7 \%$ of cases with squamous cell carcinoma. However, having only 3 cases with squamous cell carcinoma is the limitation of the study. TTF1 was not determined positive in any of the malignancies apart from lung in our study. 
Liu et al. established both TTF1 and napsin A in $83 \%$ of cases with lung adenocarcinoma, only TTF1 as positive in $4 \%$, only napsin A as positive in $9 \%$. TTF1 and napsin A were not found positive in none of extrapulmonary adenocarcinomas [28]. In our study, napsin A positivity was determined in $66,7 \%$ in lung adenocarcinoma, in addition napsin A positivity was found as positive in $66 \%$ of cases with squamous cell carcinoma.

Ordóñez et al. established napsin A positivity in $26 \%$ in squamous cell carcinoma [29]. Having napsin A positivity at $45,5 \%$ in breast cancer cases, on the other hand, having no TTF1 positivity in no cases with breast cancer contribute these two biomarkers to be used in the distinction of lung and extrapulmonary adenocarcinomas.

In a study performed in a total of 77 cases including 22 reactive mesothelial cells, 26 malignant mesothelioma and 29 metastatic adenocarcinoma by Simsir et al. calretinin was determined positive at $27 \%$ in group involving reactive mesothelial cells, $58 \%$ in malignant mesothelioma group and $31 \%$ in metastatic adenocarcinoma group and no significant difference was found between groups [30]. In our study, having calretinin at $33 \%$ in breast cancer could bring to mind that reactive mesothelial cells were also present in the fluid. Powell et al. determined calretinin positive in $15 \%$ of cases with breast cancer [31]. Ordóñez et al. established calretinin positive in $40 \%$ in squamous cell lung carcinoma [32]. In our study, there is calretinin positivity in squamous cell carcinoma.

In a study performed among patients with lung and colorectal adenocarcinoma by Kummar et al. CK7+/CK20- was determined in $96 \%$ in primary lung cancer, $95 \%$ in metastatic lung cancer [33]. In our study, CK7 positivity was identified as $20 \%$ in lung adenocarcinoma, $33 \%$ in squamous cell lung carcinoma and $27 \%$ in breast cancer. Stopyra et al. found CK7+/CK20- phenotype significantly high in breast cancer and primary colon cancer [17].

In literature, the prognostic importance of estrogen receptor was identified notably in breast and endometrium carcinoma and in a group of neuroplastic illnesses. ER (+) tumours respond to hormonal therapy and show better prognosis. In healthy lung tissue and lung tumours, there is a great deal of evidence that estrogen receptors are expressed and they respond to lung cancer with estrogen proliferation. In samples obtained from patients with non-small cell lung cancer (NSCLC), antibodies specific to $\operatorname{Er} \beta$ display that these receptors are often expressed in NSCLC $[18,34]$. In our study, we determined ER as positive in $45 \%$ in many cases with breast cancer. In pleural effusion of four cases developed after chemotherapy, determining ER as negative and CK7 as positive gave rise to thought that ER-/CK7+ of an aggressive subgroup made a metastasis in pleura. ER positivity was established in squamous cell lung carcinoma in 33\% in our study.

Tamiolakis et al. determined neuron-specific enolase (NSE) positivity in $100 \%$ in a series including 9 cases and TTF1, SYN and CgA positivity in $66 \%$ [35]. In carcinoid tumours in neuroendocrine tumour group, $\mathrm{CgA}$ positivity was reported in case series in literature. In our study, we established $\mathrm{CgA}$ positivity in a carcinoid tumour case. In $16,7 \%$ of cases with small cell lung carcinoma, CgA positivity were present in our cases. Sobol et al. found a relationship between the increase in serum CgA levels and disease activation [36]. Leucocyte common antigen (LCA-CD-45) was shown to increase in human lymphomas and leukemia in various studies. In a study published by Nakano et al. the importance of CD45 was emphasized in the differentiation of hematopoietic system and cells [37].
In our study, LCA positivity was found in lymphomas in $33 \%$. It was interpreted that $11 \%$ positivity rate could be related to the increase in inflammations in non-malignant group. Wick et al. determined LCA positivity in all 10 cases with colon and rectum small cell neuroendocrine carcinoma [38]. In the present study, LCA positivity was displayed in small cell lung carcinoma in $16 \%$.

We determined CD3 as positive in $88 \%$ of cases in non-malignant group in our study. CD3 was thought to be associated with its being a lymphocyte derived biomarker. In all 3 lymphoma cases, we established CD3 as positive. In lung adenocarcinoma, breast cancer, small cell lung carcinoma; $\mathrm{CD} 3$ positivity was observed and it gives rise to thought that this metastatic process and inflammation accompany each other. Sebastian et al. reported that they received a response for intrapleural treatment in breast cancer cases when anti $\mathrm{CD} 3$ (Catumaxomab) was applied in the treatment of malignant pleural effusions [39].

In a study carried out by Dejmek et al. CK5/6 was determined positive in 7 out of 8 mesothelioma cases and 9 out of 11 benign pleural effusion cases. In addition, they found CK5/6 positive in 11 out of 17 cases with lung adenocarcinoma and 12 out of 32 extrapulmonary adenocarcinomas; however, no significant difference was established between all groups. In pleural effusions related to NSCLC, it was reported that CK5 could be a prognostic marker [40]. $\mathrm{Pu}$ et al. found CK5/6 positive in all squamous cell cancers [41]. In our study, we determined CK5/6 positivity in $46 \%$ of cases with lung adenocarcinoma and in $66,7 \%$ of lung squamous cell carcinomas. We established positivity in $63 \%$ of cases with breast cancer and in 1 case with extrapulmonary squamous cell cancer.

CD19, CD21 and CD81 in B cells account for BHR (B Cell Receptor) complex similar to THR in T cells. CD18 was determined as positive in B cell-derived lymphoma, leukemia and inflammations. In our study, establishing CD19 positivity in $66 \%$ in non-malignant pleural effusions makes us think lymphocyte increase in effusion due to inflammation. We determined CD19 positive in all three lymphoma cases and in one extrapulmonary squamous cell carcinoma.

In the diagnosis of neuroendocrine tumours of lung; CgA and SYN are most commonly used as a marker. All typical and atypical carcinoids are $\mathrm{Cg} \mathrm{A}$ and/or SYN positive; nevertheless it is reported that they can display negativity in $25 \%$ in small cell lung cancer. In our study, SYN was determined positive in a lung carcinoid tumour case. SYN was positive in $33,3 \%$ of our cases with small cell lung cancer.

\section{Conclusion}

As a result, PCR array and pleural effusions were determined to support malignancy in lung carcinoid tumour, lung squamous cell carcinoma, breast cancer, lymphoma and lung adenocarcinoma in our study. When cytology results and PCR array results were compared, it was found out that benign determination rate of pleural effusions was $66 \%$ in both methods and malignant determination level was $73 \%$. However, that the distribution of tumour groups was not homogenous and the number of cases was less in some tumour types shows the limitation of the study.

When the results of ours study were evaluated; if cytologic workup result is negative in cases thought to be quite likely malignant pleurisy clinically (receiving treatment due to primary tumour or operated), we think that doing advanced research (primary cell culture, PCR analysis) could help diagnosis. In those whose cytologic workup result 
is positive, though, displaying biomarkers specific to tumour in fluid is considered to provide additional contribution in determining primary tumour-pleural metastasis connection. In the light of this literature, multicentered studies involving more number of cases are required.

\section{Patients' Data Protection}

\section{Confidentiality of data}

The authors declare that they have followed the protocols of their work center on the publication of patient data and that the patients included in the study have received sufficient information and given their informed consent in writing to participate in the study.

\section{References}

1. Hooper C, Lee YG, Maskell N (2010) Investigation of a unilateral pleural effusion in adults: British Thoracic Society pleural disease guideline. Thorax 65: 4-17.

2. Jay SJ (1985) Diagnostic procedures for pleural disease. Clin Chest Med 6: 33-45.

3. Vavetsi R, Bonovas S, Polizou P (2009) The diagnostic role of glycosaminoglycans in pleural effusions: A pilot study. BMC Pulm Med 9: 1471-2466.

4. Pereira C, Saad R, Liu Y, Silverman JF (2006) The diagnosis of malignancy in effusion cytology: A pattern recognition approach. Adv Anat Pathol 13: 174-184.

5. Porcel JM (2013) Pleural fluid biomarkers: beyond the Light criteria. Clinics in chest medicine 34: 27-37.

6. Francisco RP, Beatriz RR (2011) Management of malignant pleural effusions. Curr Opin Pulm Med 17: 269-273.

7. Antony VB, Leddenkemper R, Astoni P, Boutin C, Goldstraw P, et al. (2001) ERS/ATS statement: Management of malignant pleural effusion. Eur Respir J 18: 402-413.

8. Nart D, Sarsık B, Doğanavsargil B, Sezak M (2008) The importance and reliability of thyroid transcription factor-1 expression in the differential diagnosis of primary and metastatic lung tumors. Ege Tip Dergisi 47: 171-175.

9. Perner S, Wagner PL, Solterman A, LaFargue C, Tischler V, et al. (2009) TTF1 expression in non-small cell lung carcinoma: association with TTF-1 gene amplification and improved survival. J Pathol 217: 65-72.

10. Di Loreto C, Di Lauro V, Puglisi F, Damante G, Fabbro D (1997) Immunocytochemical expression of tissue specific transcription factor-1 in lung carcinoma. J Clin Pathol 50: 30-32.

11. Turner BM, Cagle PT, Sainz IM, Fukuoka J, Shen SS, et al. (2012) Napsin A, a new marker for lung adenocarcinoma, is complementary and more sensitive and specific than thyroid transcription factor 1 in the differential diagnosis of primary pulmonary carcinoma. Arch Pathol Lab Med 136: 163-171.

12. Gotzos V, Vogt P, Celio MR (1996) The calcium binding protein calretinin is a selective marker for malignant pleural mesotheliomas of the epithelial type. Pathol Res Pract 192: 47-137.

13. Andressen C, Blümcke I, Celio MR (1993) Calcium-binding proteins: Selective markers of nerve cells. Cell Tissue Res 271: 181-208.

14. Mutlu S, Güler S, Olgaç V, Alatlı C (2012) The value of the expressions of E-cadherin, calretinin and GLUT-1 in the differential diagnosis of malignant mesothelioma, reactive mesothelial proliferation and adenocarcinoma in serous effusions. Türk Onkoloji Dergisi 27: 17-23.

15. Green S, Chambon P (1991) The estrogen receptor: From perception to mechanism. In: Parker MG (Ed.) Nuclear hormone receptors. London, Academic Press pp: 15-33.

16. King WJ, De Sombre ER, Jense EV, Gren GL (1985) Comparison of immunocytochemical and steroid binding assays for estrogen receptors in human breast tumors. Cancer Res 45: 293-304.
17. Stabile LP, Davis AL, Gubish CT, Hopkins TM, Luketich JD, et al. (2002) Human nonsmall cell lung tumors and cells derived from normal lung express both estrogen receptor $\alpha$ and $\beta$ and show biological responses to estrogen. Cancer Res 62: 2141-2150.

18. Omoto Y, Kobayashi Y, Nishida K, Tsuchiya E, Eguchi H, et al. (2001) Expession, function, and clinical implications of the estrogen receptor $\beta$ in human lung cancers. Biochem Biophys Res Commun 285: 340-347.

19. Deftos LJ (1991) Chromogranin A: Its role in endocrine function and as an endocrine and neuroendocrine tumor marker. Endocr Rev 12: 181-187.

20. Mouland AJ, Bevan S, White JH, Hendy GN (1994) Human chromogranin-A gene. Molecular cloning, structural analysis and neuroendocrine cellspecific expression. J Biol Chem 269: 6918-6926.

21. Karabulut Y (2013) Chromogranin A (CgA) as bio and immunohistochemical markers. Güncel Gastroenteroloji 17: 159-162.

22. Zhang Y, Zulfiqar M, Bluth MH, Bhalla A, Beydoun R (2018) Molecular diagnostics in the neoplasms of small intestine and appendix: 2018 Update. Clin Lab Med 38: 343-355.

23. Malissen B (2003) An evolutionary and structural perspective on T cell antigen reseptor function. Immunol Rev 191: 7-27.

24. Knight SC, Stagg AJ (1993) Antigen-presenting cell types. Curr Opin Immunol 5: 374-382.

25. Gusterson BA, Warburton MJ, Mitchell D, Ellison M, Neville AM, et al. (1982) Distribution of myoepithelial cells and basement membrane proteins in the normal breast and in benign and malignant breast disease. Cancer Res 42: 4763-4770.

26. Jang KY, Kang MJ, Lee DG, Chung MJ (2001) Utility of thyroid transcription factor- 1 and cytokeratin 7 and 20 immunostaining in the identification of origin in malignant effusions. Anal Quant Cytol Histol 23: 400-404.

27. Kim JH, Choi YD, Lee JS, Lee JH, Nam JH, et al. (2010). Utility of thyroid transcription factor 1 and $\mathrm{CDX}-2$ in determining the primary site of metastatic adenocarcinomas in serous effusions. Acta Cytol 54: 277-282.

28. Liu L, Cohen C, Siddiqui MT (2012) Thyroid transcription factor 1 and napsin a double staining in lung adenocarcinoma in pleural fluid. Acta Cytol 56: 425-430.

29. Ordóñez NG (2012) A word of caution regarding napsin A expression in squamous cell carcinomas of the lung. Am J Surg Pathol 36: 396-401.

30. Simsir A, Fetsch P, Mehta D, Zakowski M, Abati A (1999) E-cadherin, Ncadherin, and calretinin in pleural effusions: the good, the bad, the worthless. Diagn Cytopathol 20: 125-130.

31. Powell G, Roche H, Roche WR (2011) Expression of calretinin by breast carcinoma and the potential for misdiagnosis of mesothelioma. Histopathology 59: 950-956.

32. Ordóñez NG (2006) The diagnostic utility of immunohistochemistry in distinguishing between epithelioid mesotheliomas and squamous carcinomas of the lung: A comparative study. Mod Pathol 19: 417-428.

33. Kummar S, Fogarasi M, Canova A, Mota A, Ciesielski T (2002) Cytokeratin 7 and 20 staining for the diagnosis of lung and colorectal adenocarcinoma. Br J Cancer 86: 1884-1887.

34. Stopyra GA, Warhol MJ, Multhaupt HA (2001) Utility of CK7 and CK20 immunohistochemistry in the detection of synchronous breast and colon carcinoma in a pleural effusion: A case report and supporting survey of archival material. Diagn Cytopathol 25: 54-58.

35. Tamiolakis D, Papadopoulos N, Cheva A, Lambropoulou M, Kotini A, et al. (2002) Immunocytochemical profile of malignant pleural effusions of small-cell lung cancer. Minerva Med 93: 479-483.

36. Sobol RE, O'Connor DT, Addison J, Suchocki K, Royston I (1986) Elevated serum chromogranin a concentrations in small-cell lung carcinoma. Ann Intern Med 105: 698-700.

37. Nakano A, Takayuki H, Shigeru M, Yuzuru K (1990) Expression of leukocyte common antigen (CD45) on various human leukemia/ lymphoma cell lines. Pathol Int 40: 107-115.

38. Wick MR, Weatherby RP, Weiland LH (1987) Small cell neuroendocrine carcinoma of the colon and rectum: Clinical, histologic, and 
Citation: Görgülü B, Akkoçlu A, Aktas S, Altun ZS, Demir AB, et al. (2018) The Importance of Investigating Tumor Biology and Biomarkers in Pleural Effusions. J Mol Biomark Diagn 9: 403. doi:10.4172/2155-9929.1000403

Page 7 of 7

ultrastructural study and immunohistochemical comparison with cloacogenic carcinoma. Hum Pathol 18: 9-21.

39. Sebastian M, Kiewe P (2009) Treatment of malignant pleural effusion with the trifunctional antibody catumaxomab (Removab) (Anti-EpCAM $\times$ Anti-CD3): Results of a phase 1/2 study. J Immunother 32: 195-202.

40. Dejmek A (2008) CK5/6 in effusions: No difference between mesothelioma and pulmonary and nonpulmonary adenocarcinoma. Acta Cytol 52: 579-583.
41. Pu RT, Pang Y, Michael CW (2008) Utility of WT-1, p63, MOC31, mesothelin, and cytokeratin (K903 and CK5/6) immunostains in differentiating adenocarcinoma, squamous cell carcinoma, and malignant mesothelioma in effusions. Diagn Cytopathol 36: 20-25. 